\title{
O PROCESSO DE TRABALHO DA ENFERMAGEM EM SAÚDE COLETIVA E A INTERDISCIPLINARIDADE*
}

Semiramis Melani Melo Rocha** Maria Cecília Puntel de Almeida**

ROCHA, S.M.M.; ALMEIDA, M.C.P.de. O processo de trabalho da enfermagem em saúde coletiva e a interdisciplinaridade. Rev.latino-am.enfermagem, Ribeirão Preto, v. 8, n. 6, p. 96-101, dezembro 2000.

Este trabalho tem por objetivo fazer uma discussão e suscitar reflexões sobre a necessidade de um diálogo interdisciplinar, quando se tem como objeto de trabalho o processo saúde-doença-cuidado. Discute a definição de enfermagem considerando sua essência, o cuidar, sua historicidade e sua prática. A seguir apresenta considerações sobre a inter e transdisciplinaridade em saúde coletiva e finaliza propondo fundamentar o cuidado na teoria da ação comunicativa de Jürgen Habermas.

UNITERMOS: cuidados de saúde, cuidados de enfermagem, saúde, doença, saúde pública

\section{INTRODUÇÃO}

As transformações que vêm ocorrendo na sociedade ocorrem também, de maneira significativa, no campo da saúde (por ser esta parte daquela), tanto no seu objeto — o processo saúde-doença-cuidado — como no instrumental teórico-prático em que se apoiam as práticas e na organização da produção em saúde. O setor saúde tem que responder a uma pluralidade de necessidades, ou seja, às demandas por intervenções tecnológicas de alta complexidade e especialidade que se dão nos hospitais de atendimento terciário e também tem que atuar nos espaços aonde as pessoas vivem o seu cotidiano, de modo a proporcionar uma vida saudável. Só a intervenção e recuperação do corpo biológico não tem respondido de forma plena às necessidades de saúde, pois estas vão além e demandam por uma atenção que leve em conta a integralidade do ser humano, a qualidade de vida e a promoção da saúde. Assim, um novo modelo assistencial vem se delineando tendo por foco de atenção a família, considerando o meio ambiente, o estilo de vida e a promoção da saúde como seus fundamentos básicos. Resgata a posição da família como importante unidade de cuidado de seus membros, entendendo que esta é o resultado de três tipos de vínculos: os de descendência, os de consangüinidade e os de afinidade. A família pode permanentemente modificar suas relações internas de acordo com as necessidades históricas, mas sempre respondendo à necessidade humana básica de comunicação, rompendo o confinamento dos laços estritos de "sangue". Em decorrência disso e das questões relativas ao custo, à eficácia, à eficiência e à cobertura dos diversos segmentos coletivos, surge a necessidade de mudanças na capacitação e formação de recursos humanos em saúde.

Estas transformações colocam novos desafios aos pesquisadores da saúde e, no caso, da enfermagem que procuram uma articulação entre o progresso técnico e as organizações sociais que sustentam a vida cotidiana.

Os impasses epistemológicos e metodológicos das ciências da saúde, diante de um objeto tão complexo - o processo saúde-doença-cuidado — ou de vários objetos que se interligam nesta complexidade, têm suscitado debates sobre novos paradigmas e novos conhecimentos em busca de sistematização.

A disciplinaridade e seus correlatos, multidisciplinaridade, pluridisciplinaridade, interdisciplinaridade, metadisciplinaridade e transdiscipinaridade, estão em evidência, atualmente, em relatos orais, ensaios como tema de aulas, quase sempre com significados distintos e de difícil compreensão (ALMEIDA FILHO, 1997). Este artigo não tem a pretensão de trazer outras contribuições para precisar estes conceitos. São utilizados autores que já se

\footnotetext{
* Trabalho financiado pelo CNPq, processos: $n^{\circ} 524507 / 96-1 ; n^{\circ}$ 524507/96-1 (SU); $n^{\circ} 524522 / 96-0$ e FAPESP processo $n^{\circ} 96-$ 12240-9

** Professoras Titulares do Departamento de Enfermagem Materno Infantil e Saúde Pública da Escola de Enfermagem de Ribeirão Preto da Universidade de São Paulo. Endereço: Av. Bandeirantes, 3900 - Monte Alegre - 14040-902 - Ribeirão Preto - São Paulo - Brasil
} 
posicionaram sobre eles, no âmbito da saúde coletiva (ALMEIDA FILHO, 1997; ALVARENGA, 1994; AYRES, 1997b; MINAYO, 1994).

Assim, este texto é um ensaio que tem como objetivo fazer uma discussão e suscitar reflexões sobre a necessidade de um diálogo interdisciplinar quando se tem como objeto de trabalho o processo saúde-doençacuidado. A enfermagem, como parte do trabalho em saúde e como uma das profissões cuidadoras vem re-construindo seu conhecimento buscando fundamentos na filosofia e em autores que epistemologicamente privilegiam a relação sujeito-sujeito.

\section{DEFININDO ENFERMAGEM}

A Enfermagem é uma das profissões da área da saúde cuja essência e especificidade é o cuidado ao ser humano, individualmente, na família ou na comunidade, desenvolvendo atividades de promoção, prevenção de doenças, recuperação e reabilitação da saúde, atuando em equipes. A enfermagem se responsabiliza, através do cuidado, pelo conforto, acolhimento e bem estar dos pacientes, seja prestando o cuidado, seja coordenando outros setores para a prestação da assistência e promovendo a autonomia dos pacientes através da educação em saúde. Há cinqüenta anos aproximadamente a enfermagem vem revisando seu conhecimento e prática, reconstruindo muitas teorias e modelos de intervenção. Em que pesem as diferenças decorrentes do contexto e clientelas para os quais foram propostas, todas as modalidades de assistência referem-se ao ambiente e seu impacto no ser humano, ao receptor do cuidado, isto é, o indivíduo, os grupos, a família e à definição de saúde em que se pauta. A enfermagem é descrita como um processo que pode integrar a relação entre estes componentes.

Alguns autores reconhecem que muito do conhecimento requerido pela enfermagem é adquirido na realidade empírica, assim, um caminho para construir uma teoria seria observar o que as enfermeiras fazem, convidálas a refletir sobre sua prática e então definir a natureza da enfermagem, partindo da base empírica de informações (WHO, 1997).

Um documento da Organização Mundial de Saúde (WHO, 1997), que trabalhou com as descrições da enfermagem em todo o mundo, demonstra que a qualificação do pessoal de enfermagem e suas atividades (sua prática) diferem profundamente de um local para outro. Concluem que, em todo o mundo, a natureza e a prática da enfermagem são influenciadas pela realidade que compreende a política, a economia e a cultura e essa realidade difere de país para país, de região para região. Em todo o mundo, entretanto, a enfermagem constitui o maior contigente da força de trabalho em cuidados à saúde. É o grupo profissional mais amplamente distribuído e que tem os mais diversos papéis, funções e responsabilidades. As enfermeiras provêm cuidados a indivíduos, famílias e comunidades que incluem promoção à saúde, prevenção de doenças, tratamentos a pacientes crônicos, agudos, reabilitação e acompanhamento de doentes terminais.

É uma profissão constituída, predominantemente, por mulheres e estas são encontradas em maior número trabalhando em hospitais, freqüentemente em unidades de emergência e de terapia intensiva, em áreas de grandes concentrações urbanas. Nas últimas duas décadas, de 80 e 90, observa-se uma mobilização da enfermagem na reorganização do setor saúde em várias regiões do mundo, dando suporte à área de atenção primária. Os enfermeiros estão também na zona rural de países pouco desenvolvidos, muitas vezes, sendo os únicos trabalhadores em saúde disponíveis, coordenando vários programas de controle de malária, tuberculose, hanseníase, diarréia, entre outros. Em muitos países encontram-se, ainda, como uma forte tradição, obstetrizes/enfermeiras obstetras trabalhando na assistência ao parto, nos cuidados preventivos e na educação em saúde.

Nas últimas décadas têm ocorrido profundas mudanças no perfil epidemiológico do processo saúdedoença, como a transição demográfica e epidemiológica com o aumento de doenças crônico-degenerativas, o reaparecimento de endemias já extintas, o envelhecimento da população, a mortalidade alta em faixas etárias jovens, devido à violência, homicídios, acidentes de trânsito e surgimento de doenças sexualmente transmissíveis como a Síndrome da Imunodeficência Adquirida.

A reestruturação do setor saúde em todo o mundo, o decréscimo relativo de leitos hospitalares, a ênfase em atenção primária e a desospitalização, bem como, a preocupação com o barateamento dos custos da atenção à saúde vêm promovendo mudanças e estão trazendo a enfermeira para o cuidado domiciliar, ambulatorial e novos espaços na comunidade, mas também sua presença se faz nos hospitais altamente especializados.

O BANCO MUNDIAL (1993) preconiza soluções ágeis, modernas e flexíveis para o setor saúde dentro de indicadores de eficácia/eficiência e custo/ benefício, bem como a importância da família como unidade de atenção das políticas sociais.

Nas escolas, as enfermeiras estão atuando não somente na atenção primária, mas também intervindo em problemas como gravidez na adolescência, doenças sexualmente transmissíveis e AIDS, nutrição, higiene, trabalho e violência infantil, drogas, alcoolismo e suicídio. $\mathrm{Na}$ assistência domiciliar, seu trabalho direciona-se para a atenção materno-infantil, gravidez de risco, 
prematuridade, doenças crônicas e pacientes terminais. Em alguns países, a enfermeira atua nas indústrias, empresas e na prevenção de acidentes de forma muito significativa. Trabalha também em equipes de planejamento e administração e na gestão de políticas de saúde.

Desta forma, constatamos que as definições e modelos de enfermagem conformados não são capazes de apreender toda a complexidade do cuidado.

Cuidar significa assistir o ser humano em suas necessidades básicas e este é o caráter universal do cuidado. Entretanto, na prática, o cuidado se apresenta de forma histórica e contextual, portanto, é variável e depende de relações que se estabelecem no processo de assistência, tornando-se uma atividade bastante complexa.

A enfermagem institucionalizada sai do âmbito familiar, privado, doméstico e insere-se na esfera pública, no século XIX, com a organização do setor saúde e das práticas médicas. Fundamenta-se, a partir daí, no conhecimento científico e adquire o mesmo caráter de racionalidade e tecnologia que domina toda a esfera produtiva da sociedade. Entretanto, pelo fato de sua essência ser o cuidado, não pode prescindir de seus aspectos afetivos, da sensibilidade e da intersubjetividade que se realiza na prática cotidiana. Varia também de acordo com a cultura, incorporando, junto com a racionalidade científica, as questões étnicas, de gênero, religiosas e éticas, entre outras.

\section{O TRABALHO DA ENFERMAGEM}

A introdução do pensamento "social" na saúde ocorreu no século XIX em alguns países europeus como França, Alemanha e Inglaterra, o que se denominou de Medicina Social. O segundo momento ocorreu após o término da $2^{\mathrm{a}}$ Guerra Mundial, nos Estados Unidos e vinte anos depois este movimento atinge a América Latina (NUNES, 1996). No Brasil, na década de 70, cunha-se a termo Saúde Coletiva e profundas questões teóricometodológicas e epistemológicas são trazidas para se redefinir este campo de saberes e práticas.

A compreensão do social no campo da saúde provocou uma ruptura com os modelos cartesianos de investigação que reduziam as relações de causa e efeito ao plano biológico e remetiam a sua resolução ao modelo clínico de diagnóstico e terapêutica. Autores como DONNANGELO (1975); DONNANGELO \& PEREIRA (1979) e, posteriormente, MENDES GONÇALVES (1979; 1994), entre outros, introduziram a categoria trabalho para entender o processo saúde-doença e as práticas de saúde em nossa sociedade. Definiu-se, então, como objeto da prática médica não mais os corpos biológicos, mas os corpos sociais e passou-se a analisar o processo saúde-doença em suas relações com a estrutura econômica, política e ideológica da sociedade. Desta forma, foi também possível apreender as formas como a medicina e as demais práticas em saúde, institucionalizadas, reproduzem as relações sociais mais amplas determinando patologias, tecnologias e formas diferenciadas de atendimento.

Partindo da apreensão dos momentos do processo de trabalho, a atividade orientada para uma finalidade, seu objeto e seus instrumentos, MENDES GONÇALVES (1994) desenvolveu um profundo raciocínio lógico e dialético para compreender as práticas em saúde, discutindo e redefinindo tecnologia.

O conceito de organização tecnológica do trabalho em saúde construído por MENDES GONÇALVES (1994) refere-se aos nexos estabelecidos no interior do processo de trabalho entre a atividade operante, realizada através de instrumentos, considerados em sentido amplo, sendo o conhecimento o principal deles porque orienta todo o processo, os objetos de trabalho e a finalidade. Portanto, tecnologia não tem o significado corriqueiro de conjunto de instrumentos materiais, muitas vezes associado à maior eficácia e produtividade por avanços em suas concepções operacionais.

Utilizando esta vertente de análise, alguns autores passaram a estudar a enfermagem enquanto uma prática social, isto é, como uma parcela do trabalho em saúde que estabelece relações sociais na produção de serviços (ALMEIDA \& ROCHA, 1986; ROCHA, 1987; SILVA, 1986; LIMA, 1995; ALMEIDA \& ROCHA, 1997).

MERHY (1997) amplia as contribuições teóricas sobre a organização tecnológica do trabalho estabelecidas por MENDES GONÇALVES (1979; 1994), trazendo a possibilidade do "auto-governo" dos trabalhadores para imprimir mudanças a partir das intersubjetividades no processo de trabalho. O autor classifica a tecnologia em saúde em dura, leve-dura e leve. Tecnologia dura referese ao instrumental complexo em seu conjunto, englobando todos os equipamentos para tratamentos, exames e a organização de informações; a leve-dura refere-se aos saberes profissionais, bem estruturados como a clínica, a epidemiologia e os de demais profissionais que compõem a equipe, estando inscrita na maneira de organizar sua atuação no processo de trabalho. A tecnologia leve produz-se no trabalho vivo, em ato, em um processo de relações, isto é, no encontro entre o trabalhador em saúde e o usuário/paciente. Neste momento de falas, escutas, criam-se cumplicidades, relações de vínculo, aceitação e produz-se a responsabilidade em torno do problema que vai ser enfrentado. 
A INTER OU A TRANSDICIPLINARIDADE NA SAÚDE COLETIVA E NA ENFERMAGEM

Estes raciocínios nos remetem à interação entre ciência, tecnologia e práticas. Alguns autores da área da Saúde Coletiva estão se preocupando com a discussão da inter ou transdisciplinaridade para apreender este objeto complexo que é o processo saúde-doença-cuidado, devido à sua natureza biológica, social, psicológica e cultural.

Nas últimas décadas, a literatura especializada sobre produção do conhecimento em saúde traz uma reflexão crítica sobre os referenciais teóricos e as questões metodológicas que procuram dar conta deste objeto tão complexo. Entende-se que as Ciências Formais, isto é, a Lógica, incluindo a Linguagem e a Matemática, constituem a base do método científico e, portanto, seriam o fundamento de um ponto de interseção entre as Ciências Naturais e Ciências Sociais onde está o conhecimento em saúde. Pela natureza de seu objeto, o processo saúdedoença-cuidado comporta o trabalho interdisciplinar em diferentes níveis, além do tratamento de temas específicos por diferentes disciplinas, de diferentes áreas com diferentes abordagens. Colocam-se então as questões ontológicas, relativas às diferentes maneiras de se conceber a natureza do objeto e as epistemológicas, decorrentes dos diferentes tipos de análise. Essas características são mais desafiadoras do que em outras áreas disciplinares, na medida em que o conhecimento deve responder não só pela diversidade de seu objeto, no interior de sistemas lógicos, com garantia de validade e veracidade como também num sistema tecnológico, com potencial de intervenção (ALVARENGA, 1994).

ALMEIDA FILHO (1997) aprofundou o debate sobre a transdisciplinaridade em saúde coletiva discutindo inicialmente aspectos históricos, epistemológicos e etimológicos do conceito de disciplina, passando a seguir a uma análise crítica dos conceitos de inter, pluri, multi, meta e transdisciplinaridade, apoiado em vários autores.

Multidisciplinaridade seria o conjunto de disciplinas que simultaneamente tratam de uma dada questão, sem que os profissionais implicados estabeleçam entre si efetivas relações no campo técnico ou científico. Pluridisciplinaridade seria a justaposição de diferentes disciplinas em um processo de tratamento de uma temática unificada, desenvolvendo relações entre si. Os objetivos seriam comuns, os campos disciplinares estariam situados em um mesmo nível hierárquico, haveria uma perspectiva de complementaridade, sem ocorrer coordenação de ações ou pretensão de criar uma axiomática comum. Metadisciplinaridade seria a interação entre as disciplinas asseguradas por uma metadisciplina situada em um nível epistemológico superior. Interdisciplinaridade implicaria em uma axiomática comum a um grupo de disciplinas conexas cujas relações seriam definidas a partir de um nível hierárquico superior ocupado por uma delas. Exigiria identificação de um problema comum, levantamento de uma axiomática teórica e/ou política básica e uma plataforma de trabalho conjunto. Transdicisplinaridade seria a radicalização de interdisciplinaridade com a criação de um campo teórico ou disciplinar de tipo novo e mais amplo. Para ALMEIDA FILHO (1997), a transdisciplinaridade baseia-se na possibilidade de comunicação não entre campos disciplinares, mas entre agentes em cada campo, através da circulação não dos discursos, mas dos sujeitos dos discursos. Não são os campos disciplinares, entidades abstratas (conceitos, noções, modelos) que interagem entre si, mas os sujeitos que os constroem na prática científica cotidiana.

Finaliza sugerindo uma síntese construída em dois níveis: uma, paradigmática no âmbito de cada campo científico e outra na prática dos agentes científicos particulares. Não seriam sínteses abstratas na esfera retórica, mas um processo exercido pelos pesquisadores em trânsito. AYRES (1997b) debatendo com ALMEIDA FILHO (1997), não se contrapõe aos seus argumentos sobre a integração de diversas ciências relacionadas a um campo de aplicação do conhecimento sob a força aglutinadora de uma nova axiomática. Vê com certo ceticismo, entretanto, a possibilidade de equipes multiprofissionais de pesquisa dissolverem as fronteiras, uma vez que as experiências têm demonstrado que, na maior parte das vezes, estes trabalhos servem mais para legitimar a permanência de rígidos domínios territoriais das ciências estabelecidas sobre os objetos complexos, com pequenas concessões cedidas em troca de um controle sob os mesmos padrões de objetividade.

Os principais problemas decorrem das seguintes questões: a suposta universalidade do método científico aplicável a todas as ciências; o reducionismo teórico e metodológico do método científico; se há ruptura ou não do conhecimento científico com o conhecimento do senso comum; a concepção de racionalidade científica para além de seu caráter de objetividade e neutralidade. Se para o campo das Ciências Sociais e Humanas tais problemas se colocam, eles aparecem de forma muito mais grave para o pesquisador em Saúde, isto é, ao se pensar a Saúde Coletiva inscrita entre as Ciências Naturais, Formais e Sociais, evidenciam-se mais explicitamente as implicações teóricas e metodológicas desta interdisciplinaridade. O grande problema que se coloca, portanto, é a necessidade de adoção ou criação de novos esquemas teóricos e metodológicos de explicação no interior da relação entre ciência, filosofia e tecnologia.

Para alguns autores (MINAYO, 1994; AYRES, 1997a), a teoria da ação comunicativa de HABERMAS 
(1988), que propõe a articulação entre a filosofia, a ciência e o mundo da vida como uma nova forma de relação dialética entre o sujeito e o objeto na construção do conhecimento pode ser uma alternativa para se contrapor à razão instrumental que domina a sociedade moderna.
...entendo por ação comunicativa uma interação simbolicamente mediada. Ela orienta-se segundo normas de vigência obrigatória que definem as expectativas recíprocas de comportamento e que têm de ser entendidas e reconhecidas, pelo menos, por dois sujeitos agentes. As normas sociais são reforçadas por sanções. O seu sentido objetiva-se na comunicação lingüística quotidiana. Enquanto a validade das regras e estratégias técnicas depende da validade de enunciados empiricamente verdadeiros ou analiticamente corretos, a validade das normas sociais só se funda na intersubjetividade do acordo acerca de intenções e só é assegurada pelo reconhecimento geral das obrigações (HABERMAS, 1994).

$\mathrm{Na}$ teoria do agir comunicativo, HABERMAS (1988) desenvolve, como uma das idéias centrais, a crítica ao estreitamento do conceito de racionalidade às suas dimensões cognitivo-instrumentais, deixando de lado os elementos ético-normativos e estético-subjetivos. Para que a sociedade dê um salto de qualidade, HABERMAS (1988) propõe construir uma filosofia crítica que se apoie em dois eixos complementares: a atividade comunicativa e a razão comunicativa. A filosofia não reduziria seu papel a um posicionamento apenas crítico em relação à sociedade contemporânea, mas ampliaria sua atividade, fazendo a mediação entre a filosofia e as ciências. Em um processo de cooperação interdisciplinar, a filosofia passa a ser mediadora entre os especialistas em ciência e tecnologia e o mundo da vida cotidiana.

A cooperação interdisciplinar manteria
atitudes críticas fundamentais, de um lado,
em relação à racionalidade técnica,
instrumental è à ideologia tecnocrática; de
outro, em relação à tentativa de colonização
do mundo vital pela ciência e pelas
tecnologias sofisticadas e à ideologia que
as justifica (MINAYO, 1994).

A proposta de mudança de paradigma desloca o sujeito como sendo aquele que se relaciona externamente com os objetos para conhecê-los, agir e dominá-los e coloca os sujeitos em interação com outros sujeitos, preocupados todos com o que pode significar conhecer objetos, pessoas e coisas.

Segundo MINAYO (1994), um dos temas que sobressai desta reflexão é a questão da validação científica. O princípio de hierarquia entre as ciências é substituído pelo princípio da cooperação possibilitando a transitividade interna na discussão dos conceitos e linguagens. Além disso, a validade interna não responde sozinha pelo valor do conhecimento como tem sido colocado tradicionalmente. Todo discurso científico, para ser válido tem exigências, pretensões e condições. A validação científica passa a abranger três aspectos: a validade normativa, que abrange os aspectos de adequação de métodos e técnicas ao desenvolvimento do objeto ou da proposição; a validade proposicional que verifica a relevância do objeto e da proposta para a ciência e para as necessidades reais do mundo da vida; a validade expressiva/autenticidade que confere significado às descobertas científicas pela possibilidade de comunicação, através da argumentação no "dialogo de muitas vozes".

Retomando o processo saúde-doença-cuidado, verificamos que a lógica instrumental dá sustentação ao trabalho em saúde que se apoia na fisiopatologia para o diagnóstico, a terapêutica e obtém relativos sucessos se considerarmos como resultado a restauração biológica. Entretanto, se considerarmos a experiência, isto é, o significado do padecimento, o vivido existencialmente durante o processo, precisamos pensar no limite da intervenção, na forma como estabelecemos o cuidado e nas associações entre o cuidado e o processo diagnóstico que permitem atuar na intervenção. Aqui faz sentido uma postura ativa de inter-relação e diálogo interdisciplinar relacionado aos diversos conhecimentos num projeto de construção solidária do cuidar.

Se aceitarmos a teoria de HABERMAS (1988), a validade do conhecimento objetivo repousa na intersubjetividade vivida. A pretensão de verdade de um discurso é sempre vinculada ao seu valor por referência aos três níveis de validação já mencionados: a) na sua efetividade em instruir ações legítimas no âmbito dos projetos sociais relativos a tais realidades, isto é, na sua correção normativa; b) na sua capacidade de expressar certezas compartilháveis, isto é, na sua verdade proposicional; e c) no êxito em estabelecer efetiva comunicação entre os diversos sujeitos envolvidos nessas ações, isto é, na sua autenticidade expressiva (AYRES, 1997a).

Portanto, o conhecimento capaz de fundamentar o cuidado de enfermagem deve ser construído na intersecção entre a Filosofia, que responde à grande questão existencial do homem, a Ciência e Tecnologia, tendo a lógica formal como responsável pela correção normativa, e a Ética, isto é, numa abordagem epistemológica efetivamente comprometida com a emancipação humana. 


\section{THE PROCESS OF NURSING WORK IN COLLECTIVE HEALTH AND INTERDISCIPLINARY STUDIES}

This study aims at discussing and stimulating reflections on the need of an interdisciplinary dialogue when the object of work is the health-illness-care process. The authors discuss the definition of Nursing by considering its essence, care, its history and practice. Following, considerations about inter-and trans-disciplinary studies on collective health are presented and the authors conclude with a proposal of basing care on the theory of communicative action developed by Jürgen Habermas.

KEY WORDS: health care, nursing care, health, disease, public health

\section{EL PROCESO DE TRABAJO DE LA ENFERMERÍA EN SALUD COLECTIVA Y LA INTERDISCIPLINARIDAD}

Este trabajo tiene por objetivo hacer una discusión y suscitar reflexiones acerca de la necesidad de un diálogo interdisciplinar, cuando se tiene como objeto de trabajo el proceso salud-enfermedad-cuidado. Discute la definición de enfermería considerando su esencia, el cuidado, su historicidad y su práctica. Además, se presentan consideraciones sobre la inter y transdisciplinaridad en salud colectiva y finalmente propone basar el cuidado en la teoría de la acción comunicativa de Jürgen Habermas.

TÉRMINOS CLAVES: cuidados de salud, cuidados de enfermería, salud, enfermedad, salud pública

\section{REFERÊNCIAS BIBLIOGRÁFICAS}

01. ALMEIDA FILHO, N. Transdisciplinaridade e Saúde Coletiva. Ciência \& Saúde Coletiva, Rio de Janeiro, v. 2, n. 1/2, p. 5-23, 1997.

02. ALMEIDA, M.C.P.; ROCHA, J.S.Y. O saber de enfermagem e sua dimensão prática. São Paulo: Cortez, 1986.

03. ALMEIDA, M.C.P.; ROCHA, S.M.M. (org.). O trabalho de enfermagem. São Paulo: Cortez, 1997.

04. ALVARENGA, A.T. A saúde pública como campo de investigação interdisciplinar e a questão metodológica. Saúde e Sociedade, São Paulo, v. 3, n. 2, p. 22-41, 1994.

05. AYRES, J.R.C.M. Sobre o risco: para compreender a epidemiologia. São Paulo: Hucitec, 1997a.

06.AYRES, J.R.C.M. Deve-se definir transdisciplinaridade? Ciência \& Saúde Coletiva, Rio de Janeiro, v. 2, n. $1 / 2$, p. 36-38, 1997 b.

07. BANCO MUNDIAL. BANCO INTERNACIONAL DE RECONSTRUCCIÓN Y FOMENTO. Informe sobre el desarrollo mundial. Washington, 1993.

08. DONNANGELO, M.C.F. Medicina e sociedade: o médico e seu mercado de trabalho. São Paulo: Pioneira, 1975.

09. DONNAGELO, M.C.F.; PEREIRA, L. Saúde e sociedade. São Paulo: Duas Cidades, 1979.

10. HABERMAS, J. Teoria de la acción comunicativa. Madrid: Taurus, 1988.
11. HABERMAS, J. Técnica e ciência como ideologia. Lisboa: Edições 70, 1994.

12. LIMA, R.A.G. A enfermagem na assistência à criança com câncer. Goiânia: AB, 1995.

13. MENDES GONÇALVES, R.B. Medicina e história: raízes sociais do trabalho médico. São Paulo, 1979. 209p. Dissertação (Mestrado) - Faculdade de Medicina, Universidade de São Paulo.

14. MENDES GONÇALVES, R.B. Tecnologia e organização social das práticas de saúde: características tecnológicas do processo de trabalho na rede estadual de Centros de Saúde de São Paulo. São Paulo: Hucitec/Abrasco, 1994.

15. MERHY, E.E. A perda da dimensão cuidadora na produção da saúde: uma discussão do modelo assistencial e da intervenção no seu modo de trabalhar a assistência. Campinas, DMPS/FCM/ UNICAMP, 1997.

16. MINAYO, M.C.S. Interdisciplinaridade: funcionalidade ou utopia? Saúde e Sociedade, São Paulo, v. 3, n. 2, p. 42-63, 1994.

17. NUNES, E.D. Saúde coletiva: revisitando a sua história e os cursos de pós-graduação. Ciência \& Saúde Coletiva, Rio de Janeiro, v. 1, n. 1, p.5569, 1996.

18. ROCHA, S.M.M. Puericultura e enfermagem. São Paulo: Cortez, 1987.

19. SILVA, G. B. Enfermagem profissional: análise crítica. São Paulo: Cortez, 1986.

20. WORLD HEALTH ORGANIZATION. Nursing practice around the world. Geneva, 1997.(Nursing/Midwifery - Health Sistems Development Programme). 